\title{
Holistic modelling approach for special concrete: from fresh- to hardened-state
}

\author{
Sergio H.P. Cavalaro ${ }^{a^{*}}$, Ana Blanco ${ }^{a}$, Ricardo Pieralisi ${ }^{b}$ \\ a Loughborough University, Loughborough, UK \\ b Universidade Federal do Parana, Curitiba, Brazil
}

Received: 22 August 2018 / Accepted: 11 January 2019 / Published online: 18 January 2019

(C) The Author(s) 2019. This article is published with open access and licensed under a Creative Commons Attribution 4.0 International License.

\begin{abstract}
In the construction industry, the design of dimensions of structural elements and material properties is generally separated from the design of material composition and of the production processes used. Such divide is enabled by robust construction materials (like concrete) little affected by production processes if minimum precautionary measures are in place. The same does not hold true for special concrete types; whose higher sensitivity to the mix design and manufacturing compels a shift towards more comprehensive approaches that incorporate the production process into a holistic design. The design driven by integrated numerical simulations encompassing from production to the long-term performance is already ordinary in the manufacturing of plastic and metallic components. Nevertheless, it remains an alien to the construction industry. The objective of this paper is to review existing studies that might underpin this holistic design approach in construction and show some of its capabilities. Advanced modelling strategies available to simulate the behaviour from the fresh- to the hardened-state are discussed for the cases of pervious concrete and fibre reinforced concrete. This approach provides a deeper insight about the material behaviour and aids to a new level of numerical optimisation of their compositions and production processes, unlocking a potential transformation of the modus operandi of the construction industry.
\end{abstract}

Keywords: Modelling; Pervious concrete; Fibre reinforced concrete; Fresh-state; Hardened-state

\section{Introduction}

Since the birth of steel reinforced concrete as a building material in the $19^{\text {th }}$ century, there has been a divide between design and construction. Designers work with models estimating dimensions of the structural elements and material properties that satisfy a certain performance level; constructors work to find a composition that satisfies these properties and to produce the elements. Part of the successful, widespread use of concrete comes from an implicit symbiosis between designers and constructors, combined with the robustness of a material not hugely affected by the production process if elements are properly cast and cured. For instance, conventional reinforced concrete beams tend to show similar performance regardless of the initial casting position or path (from centre or from ends). Likewise, in a well compacted column, a slight increase in energy of vibration should not induce massive changes in the final performance of the element.

This does not hold true for all applications or types of concrete. Particularly for special types with added functionality or executed in extreme conditions, the production process might have a significant influence on the behaviour achieved. Fibre reinforced concrete (FRC) is an example of how processes occurring in the fresh-state can significantly affect the performance in the hardened-state. Discrete fibres dispersed in the matrix enhance its ductility, post-cracking strength, cracking and fire resistance in underground construction, pavements and in the precast industry. The behaviour of hardened FRC is governed by the strength of the matrix and by fibre distribution and orientation, which depend on the rheological properties, the casting procedure and the geometry of the element produced. Changes of more than $100 \%$ on the mechanical residual strength have been reported in the literature depending on the direction of testing or the production process adopted [1-4].

Another example in which production processes have major influence on the hardened-state performance is found for pervious concrete (PC) - generally used in pavements and insulation layers. This material shows high permeability owed to a reduction in the content of fine aggregates in the composition, which tends to decrease the mechanical performance. After mixing, PC is transported, placed and generally compacted to a given density. The same composition may lead to a highly pervious or an almost impervious concrete depending on the level of compaction introduced $[5,6]$.

* Corresponding author: Sergio H.P. Cavalaro, E-mail: S.Cavalaro@lboro.ac.uk 
The diversity of factors affecting the successful application of these special concrete types entails an added level of complexity that compromises the implicit symbiosis designconstruction mentioned previously. This is a potential source of problems and uncertainties as the material might comply with the design requirements at a laboratory quality assurance test but not at a real-scale element, thus creating a barrier for reliable, widespread applications. Evidently, the traditional design approach for conventional concrete elements does not suffice the needs of these special types of concrete.

To overcome such issues, the design of material properties must be linked to a design of production processes, both based on predictive numerical models [7]. This philosophy broadly applied in the manufacturing industry - is still an alien to the construction industry, which lacks the appropriate tools and resources to deploy a more holistic design from the fresh- to the hardened-state, including all intervening production processes. The advent of accessible systems with higher computing power will enable this philosophy, essential for the evolution of concrete as a building material. The objective of this paper is to show existing studies that might underpin this holistic approach and show some of its capabilities.

\section{Fibre reinforced concrete}

\subsection{Modelling strategy}

The holistic approach to assess the performance of FRC should couple 2 models, as shown in Fig.1. The first simulates the fresh-state behaviour over the stages of production of the elements (i.e. mixing, transport, casting and vibration or compaction) to assess the fibre distribution and orientation after completion. The second simulates the hardened-state behaviour considering the fibre distribution and orientation obtained in the previous stage to assess a global mechanical response.

The fresh-state behaviour of FRC has been simulated in the literature using multi-phase Computational Fluid Dynamics (CFD) $[8,9]$ and Discrete Element Models (DEM). In the former, the matrix is treated as a fluid and fibres behave as solid inclusions that interact with the flow. A 1-way interaction may be assumed (fibres are affected by the flow but do not modify it) for small volume of inclusions, while a 2- way interaction (fibres are affected and modify the flow) is recommended for high contents.

In the DEM, the fresh matrix is represented by spherical particles whose interaction are defined by Newton's motion laws. The contact between particles is usually simulated with a Kelvin rheological model that includes elastic and viscous components in the normal direction represented by a spring and a dumper in parallel. Fibres are defined as clumps of spherical particles bonded together. The fibres-matrix interaction is generally modelled using a Bingham rheological model in the normal direction, which consists of a Saint Venant element and a dashpot connected in parallel. Deformation is limited until the yield stress is reached, when the model exhibits visco-plastic deformation. Other studies have used alternative approaches, such as 3-dimensional Lagrangian smooth particle hydrodynamics, to simulate the flow of FRC $[10,11,12]$.

In the hardened-state, the tensile or flexural behaviours of FRC are usually simulated using sectional analysis or Finite Element Models (FEM) considering a homogeneous material with a non-linear constitutive law that represents the interaction between concrete and fibres as a continuum. Since fibres are not treated as discrete elements, their orientation and distribution must be introduced via input parameters obtained in back analysis of experimental results. Authors $[13,14]$ have developed more complex FEM that simulate each fibre discretely, accounting for their interaction with the surrounding matrix. This allows the consideration of distribution and orientation but comes at a high computational cost. It also brings convergence issues as many fibre-matrix interfaces are generated and complex localized cracking of the matrix occurs around the fibre during the pullout stage.

An alternative approach was proposed by Cavalaro and Aguado [16] to account for the contribution of each fibre and mitigate these disadvantages. To reduce the computational cost, only fibres crossing the cracked surface are modelled. These are identified in a preliminary stage by the position of their extremities with regards to the cracked plane (see Fig.1). To reduce convergence issues due to localized cracking, individual fibres are represented by a 2-point interface element ( 1 at each sides of the cracked surface). The interfaces follow specific pull-out curves of each fibre calculated using models from the literature.

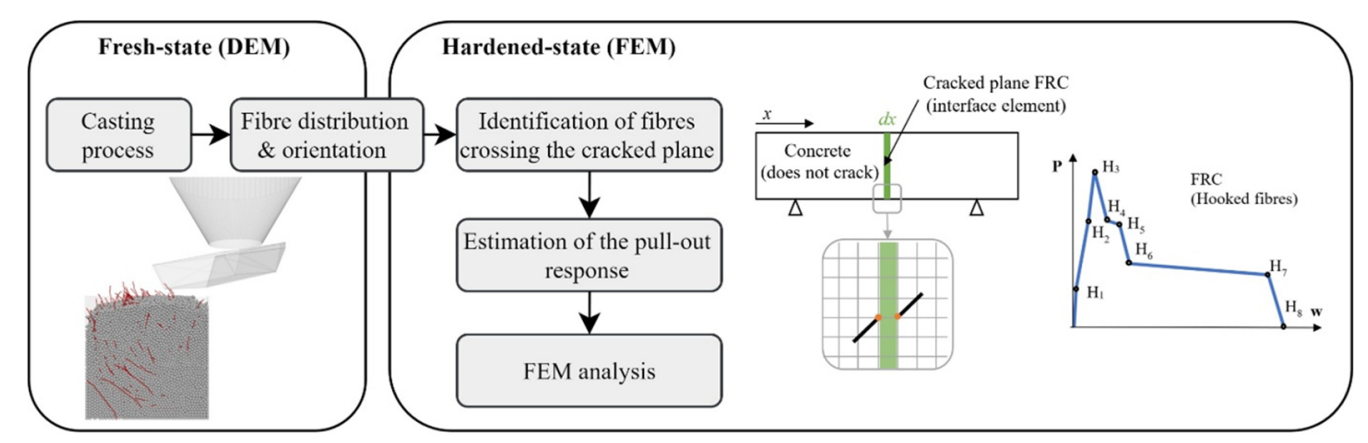

Figure 1. Holistic modelling strategy to assess the behaviour of FRC. 
These pull-out models usually depend on input parameters relating to the fibre (diameter, embedded length, tensile strength and inclination with the crack surface and with the load direction), the matrix (average tensile strength) and key points of the load-crack opening curve obtained from pull-out tests of a single or multiple fibre. Among the alternatives from the literature [17-20], Cavalaro and Aguado [16] chose the pull-out models proposed by Laranjeira for straight [21] and hooked-end fibres [22]. Fig.1 shows a schematic diagram of the pull-out curve with the key points for hooked fibres. The input parameters and the models are further described by Laranjeira et al. [21,22], including validations with results from Leung [23], Robins [24] and Van Gysel [25]. The pull-out curve estimated for each fibre is introduced in the FEM that is processed to determine the global structural response of the specimen. The model is adequate to simulate specimens with a preferential cracking plane and softening behaviour. In case hardening occurs, additional interface elements must be placed to account for multiple cracking.

\subsection{Capabilities of the approach for FRC}

The hardened-state model from Cavalaro and Aguado [16] was used to simulate bending tests according to BS EN 14651:2005+A1:2007 [26] conducted by Blanco [27] in concrete specimens with $20 \mathrm{~kg} / \mathrm{m}^{3}$ of hooked-end steel fibre. The fibre distribution for a highly fluid concrete measured in several experimental programmes with an inductive method [28-30] was assumed. Fibres were generated inside the specimen following probabilistic the law described by Cavalaro and Aguado [16]. Pull-out parameters of the fibre were calibrated to guarantee the fit between experimental and numerical results. As expected, a good fit is observed for the whole extent of the average curves, as shown in Fig. 2.

Although the fibre average orientation is nearly the same in all models generated with identical input parameters, slight differences in position and inclination occur due to the randomness of fibre distribution. Consequently, a different
load-CMOD curve is obtained every time a geometry is generated and processed, producing a numerical scatter similar to that found in experimental programmes. This enables studies of the influence of different parameters (e.g. size of specimen, fibre content or type of concrete) in the structural response and the intrinsic scatter of the material [16].

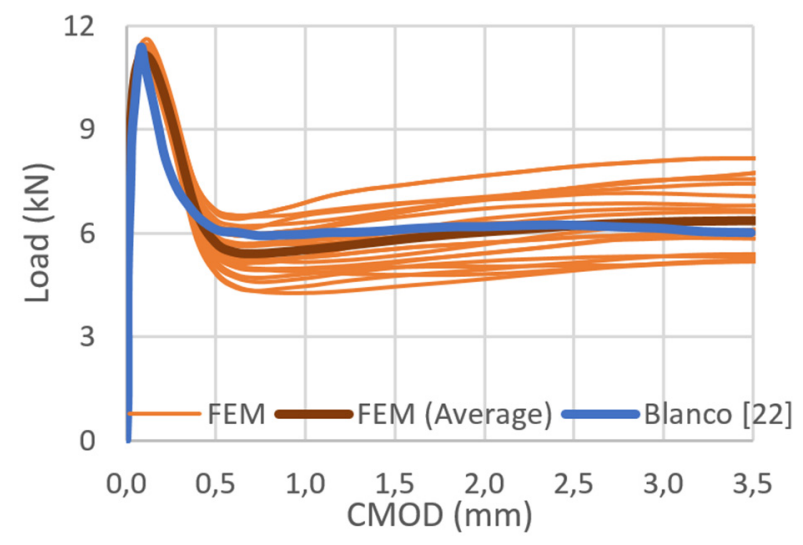

Figure 2. Experimental [27] and numerical results.

The influence of the geometry of the specimen on the postcracking response is assessed in terms of the equivalent flexural residual strengths $f_{R 1}$ and $f_{R 4}$ in a 3PBT configuration used by the Model Code 2010 [31] to estimate the constitutive equation of FRC. Fig. 3 shows the evolution of both residual strengths with the width of the specimens with heights of $150 \mathrm{~mm}$ (H150), $200 \mathrm{~mm}$ (H200) and $300 \mathrm{~mm}$ (H300). Each point in Fig.3 is an average of at least 20 simulations considering the wall effect induced by the formwork. Notice that specimens $\mathrm{H} 150$ with width $150 \mathrm{~mm}$ do not correspond to the standard specimen defined in EN14651 as no notching is applied in these models. a)

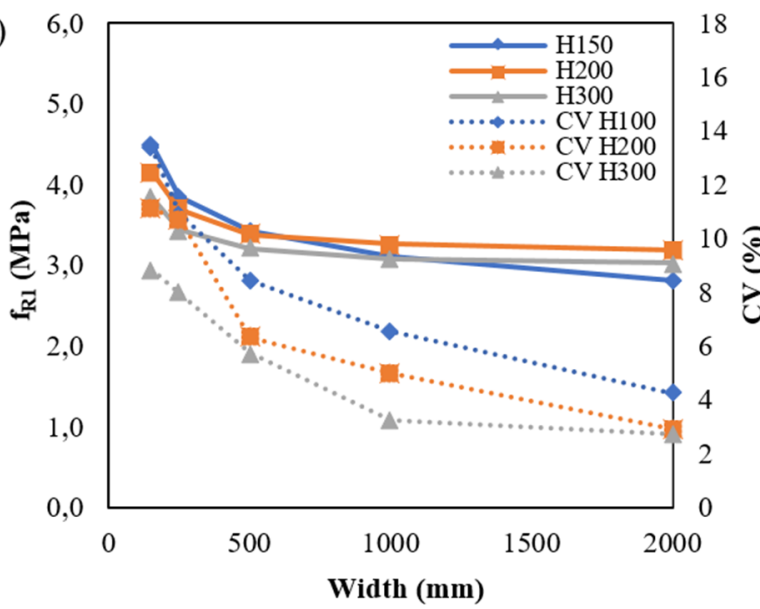

b)

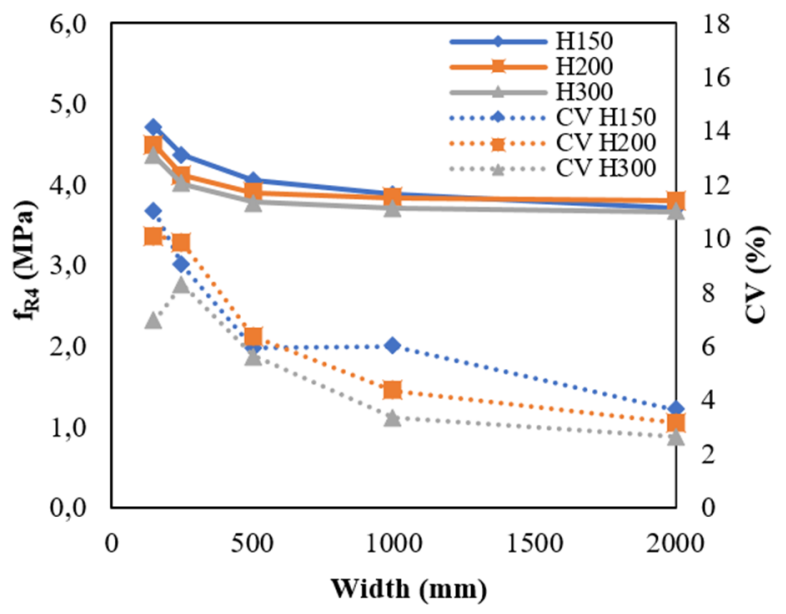

Figure 3. Average and coefficient of variation assessed for a) $f_{R 1}$ and $b$ ) $f_{R 4}$. in specimens with different cross-sections subjected to $3 P B T$. 
Fig. 3 reveals that $f_{\mathrm{R} 1}$ and $f_{R 4}$ decrease as the width of the specimen increases. For instance, an increase in width from $150 \mathrm{~mm}$ to $2000 \mathrm{~mm}$ in specimens $\mathrm{H} 150$ leads to a reduction of $37.7 \%$ and $21.3 \%$ in $f_{R 1}$ and $f_{R 4}$, respectively. The results also suggest that higher specimens tend to exhibit smaller flexural residual strengths. The residual strength reduction observed with the increase of the cross-section size is a consequence of the wall-effect of the formwork. In small elements, the formwork influences the fibre orientation in a significant portion of the cross-section, thus promoting a favourable preferential fibre alignment perpendicular to the crack. Conversely, in bigger elements, the wall effect modifies the orientation of fibres located in a smaller proportion of the cross-section, allowing fibres to assume less favourable orientations with the cracking plane. Notice that $96 \%$ of the cross-section of $\mathrm{H} 150$ with $150 \mathrm{~mm}$ of width is affected by the wall-effect, against only $22.4 \%$ for H300 with 2000 mm of width.

Fig. 3 also shows the intrinsic coefficient of variation (CV) of $f_{\mathrm{R} 1}$ and $f_{R 4}$ from the numerical simulations (not considering the variability induced by production and testing processes). A significant reduction in CV occurs as the cross-section size increases. Similar results were already reported in the literature [32-36] and in numerical studies by Cavalaro and Aguado [16]. Although the wall-effect also contributes to this outcome, the main cause is the variability in the number of fibres effectively bridging the crack. Specimens with smaller cross-section have a reduced number of fibres contributing to the residual strength. Slight variations in the number of fibres from one model to another may lead to significant changes in the residual response, augmenting the CV. By contrast, the increase in cross-section size also increases the number of fibres bridging the crack, diluting the influence of variations in the number of fibres in the cracked plane from one model to another and, thereby, the CV.

Fig. 4 shows the average and the $\mathrm{CV}$ of $f_{R 1}$ and $f_{R 4}$ estimated for specimens $\mathrm{H} 150$ with $150 \mathrm{~mm}$ of width and those for specimens of the same size that received a $25 \mathrm{~mm}$ notch $(\mathrm{H} 125)$, as specified in EN14651. According to the results, $f_{R 1}$ and $f_{R 4}$ are respectively $42.9 \%$ and $14.5 \%$ bigger for the specimen without the notch, which again is consistent with the notch sensitivity experienced by quasi-brittle materials and may be explained by the influence of the wall-effect. The notch deactivates fibres located closer to the formwork, which were more likely to have a favourable orientation perpendicular to the crack.
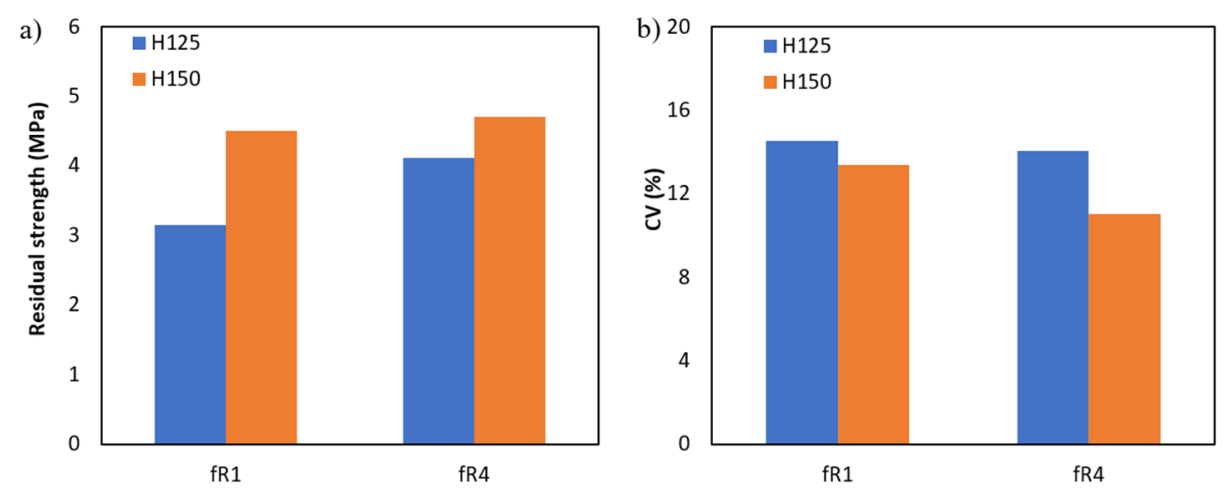

The $\mathrm{CVs}$ of $f_{R 1}$ and $f_{R 4}$ are respectively $8.1 \%$ and $21.7 \%$ smaller for the specimen without the notch. This is due to the bigger failure surface of the specimen without the notch, which contains more fibres crossing the cracked section, reducing the influence of variations in the number of fibres. Notice that these simulations consider a pre-defined position of the crack due to the presence of the notch. Specimens without the notch crack in the weakest section, hence these variations in the crack position could lead to an increase in scatter of specimens.

\section{Pervious concrete}

\subsection{Modelling strategy}

Fig. 5 shows the holistic strategy for assessing the permeability and strength of PC. The integrated model combines discrete element method (DEM) - to simulate the compaction process in the fresh state, obtain the meso-structure and model the mechanical behaviour - with computational fluid dynamics (CDF) - to predict the flow profile and permeability of the meso-structure.

Few studies are reported in the literature regarding the simulation of the compaction of PC. Studies either employ lattice models [36] or DEM [6]. In the DEM, aggregates are generally considered bi-phasic spherical particles, formed by an inner core (aggregate) and an external layer (surrounding cement paste). The interaction between particles during the compaction are defined by force-displacement laws. The normal interaction between the external layers of the particles are simulated using a Kelvin-Voigt model aligned with an additional spring and a dumper, whereas the normal contact between inner cores is modelled with a purely elastic interaction law. Tangential interactions follow a modified Bingham-Hooke law [6]. During the compaction process, the separation between particles is reduced and the paste surrounding the aggregate is pushed away from the initial contact point due to its visco-elastic rheology. Hence, the cement paste is redistributed, the lateral volume increases and a meniscus or contact bridge (CB) is formed. The $3 \mathrm{~d}$ mesostructure generated after compaction is formed by the solid phase (aggregates and cement paste) and the pore phase (voids between particles).

Figure 4. Results for $\mathrm{H} 125$ and $H 150$ : a) average and b) $C V$ for $f_{R 1}$ and $f_{R 4}$. 


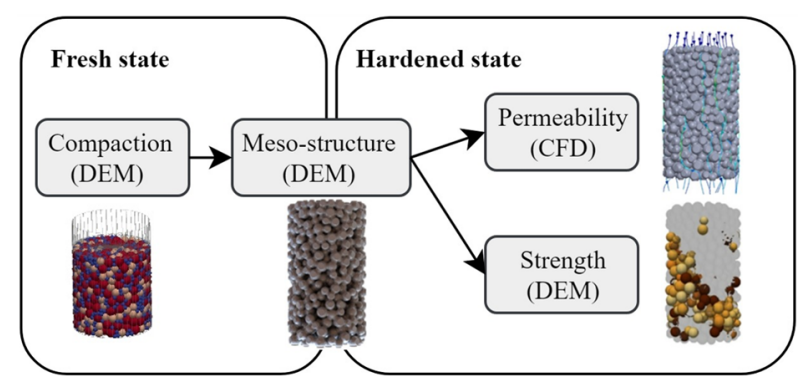

Figure 5. Modelling strategy to assess the permeability and strength of PC

The permeability of the hardened PC is assessed by meshing the porous phase and the surface of the solids since the water flow is governed by the voids. More details on the mesh generation and mesh refinement can be found in [37]. The proper consideration of the CB's geometry is paramount given its influence in the total volume of voids and the tortuosity of the system, thus affecting the porosity and permeability. After generating the mesh, Navier-Stokes equations may be used to predict the flow [37]. A similar methodology is found in Zhang et al. [38], who simulated the permeability by meshing the porous phase obtained through computed tomography.

The mechanical performance of PC may be assessed in terms of the pre-cracking and post-cracking strength in tension and compression using either FEM or DEM. The DEM is the most commonly found in the literature $[39,40]$ and account for two types of particle interactions: cohesive and non-cohesive. The latter is associated to the bond between cement paste and aggregates (might involve a degree of damage depending on the load level), whereas the latter represents a fully damaged contact or new interactions between particles not initially in contact. The cohesive constitutive law transmits tensile and compressive forces in the normal direction and shear forces in the tangential direction, whereas the non-cohesive interaction transmits only compression forces in the normal direction and friction forces in the tangential direction.

\subsection{Capabilities of the approach for PC}

The meso-structures obtained in DEM simulations of the compaction process were used to assess the permeability via

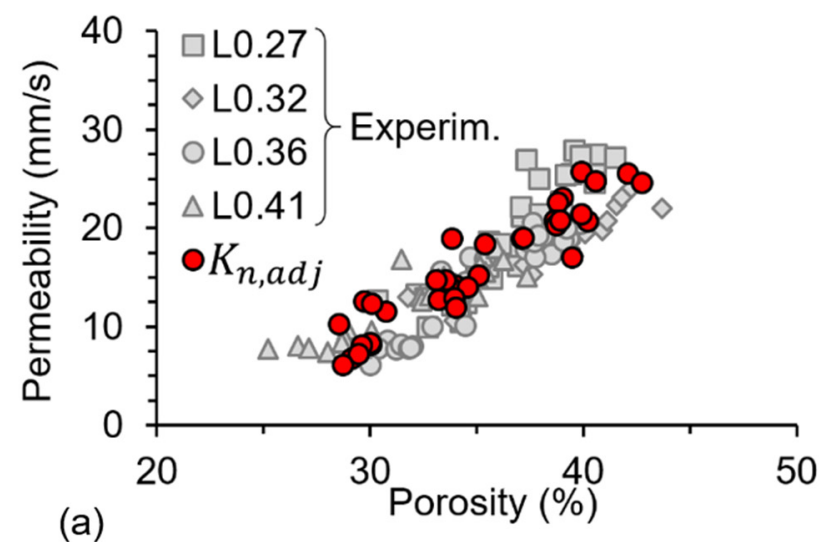

CFD simulations and the mechanical properties via DEM simulations according the procedure described in [41]. Fig.6a shows the experimental and numerical results for the permeability and the porosity of four PC mixes categorised by the weight ratio between paste and aggregate $(\mathrm{P} / \mathrm{A})$ in the composition. Degrees of compaction (DoC, expressed in terms of the ratio between the reduction of height and the initial height of the specimen) of $10 \%, 15 \%$ and $20 \%$ were simulated. The permeability of all mixes was multiplied by a constant factor (Kn,adj) regardless of their P/A and DoC to compensate for simplifications regarding the shape (considered as perfect spheres) and size distribution (three different sizes) of the aggregates. Fig.6b presents the correlation between experimental and numerical permeability coefficients.

The trueness (estimation of the systematic error) of the results is $0.00 \mathrm{~mm} / \mathrm{s}$ and the precision is $2.27 \mathrm{~mm} / \mathrm{s}$, with an average prediction error of $0.11 \%$. The good agreement between experimental and numerical results confirms that small corrections for the simplifications assumed are sufficient to ensure a robust model sensitive to variables such as $\mathrm{P} / \mathrm{A}$ and DoC.

The model allows assessing characteristics extremely difficult to evaluate experimentally, such as the fluid flow streamline and how it is affected by the tortuosity of the meso-structure. Fig.7a shows the variation of the velocity of the fluid in the cross-section. Fig.7b shows the tortuosity (ratio between height of the specimen and average length of the path taken by the fluid passing through the specimens) against the porosity for mixes with different $P / A$.

Increases of the P/A (increasing the cement paste content) from 0.27 to 0.41 has a small influence on total porosity, in the path of the flow streamline and in the tortuosity. The results show a non-linear relation between porosity and tortuosity, where the latter increases significantly as porosity decreases. Given the influence of porosity and tortuosity on the permeability coefficient, these results also suggest a nonlinear relation between the porosity and the permeability coefficient.

Figure 6. Experimental and numerical permeability coefficient: a) versus numerical porosity and b) direct comparison [42].

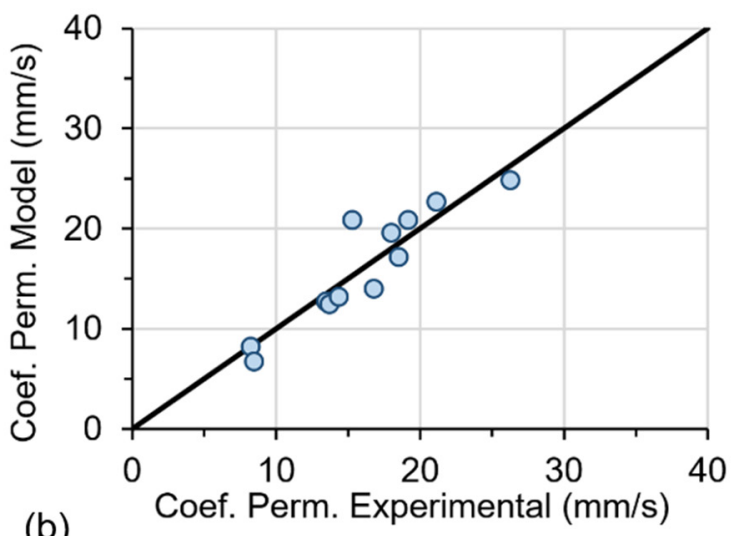

(b) 
Fig. 8 shows the experimental and numerical results for the compressive and tensile strengths depending on the porosity of the matrix. The scatter yielded by the model is similar to that observed experimentally both for the compressive and the tensile strength, which confirms the ability of the model to reproduce the variability of PC. A good fit is observed regardless of the variation in the $\mathrm{DoC}$ and $\mathrm{P} / \mathrm{A}$.

\section{Conclusions}

This paper describes holistic modelling approaches for special types of concrete highly influenced by their fresh-state behaviour and the production process. The potential of a discrete modelling philosophy was demonstrated for FRC (whose behaviour is governed by the fibre distribution and orientation) and for PC (whose permeability and mechanical performance depends on the compaction process). Evidences included here suggest that existing numerical models can simulate the fresh- and hardened-state properties of these materials, providing results that agree with those obtained in experimental programmes.

From a scientific standpoint, this approach enables a deeper understanding on how the composition and production process affect the meso-structure and the properties of the hardened material. From a practical standpoint, it opens the possibility of an integrated numerical design of material composition and production process to maximize performance or to suit requirements from specific applications. This might reduce the dependency on experimental studies in an area traditionally dominated by trial and error. Experimental studies will remain an essential step to confirm predictions and further optimize the performance due to simplifications assumed in the numerical models.

Additional research is still required to enhance the representativeness of the models. For instance, a more detailed representation of the shape of the aggregate might increase the accuracy of the predictions from the compaction, flow and mechanical models of PC. In the case of FRC, more studies about the validation of the fibre distribution in the fresh state connected with the mechanical performance are required, also considering other types of fibre (e.g. plastic and glass). These developments might contribute to modernise the current modus operandi of the construction industry.

\section{Acknowledgements}

The first author thanks RILEM for the recognition and for the honour received via the Gustavo Collonetti Medal. The third author thanks the Ministry of Education of Spain for the FPU Scholarship (AP2012-4188).

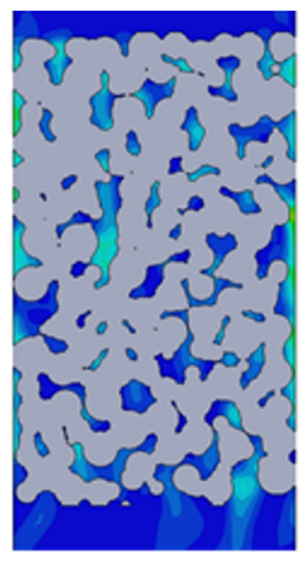

(a)

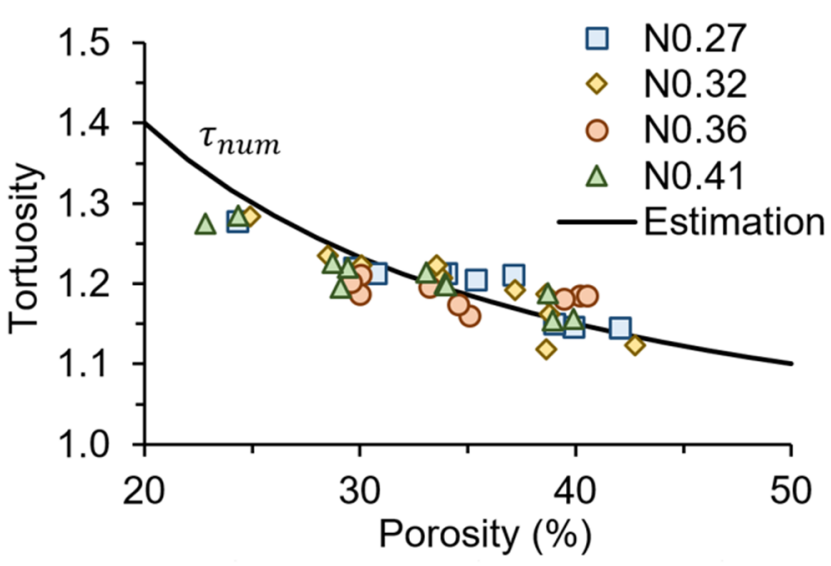

(b)

Figure 7. a) Flow velocity in the cross-section and b) tortuosity versus porosity [42].
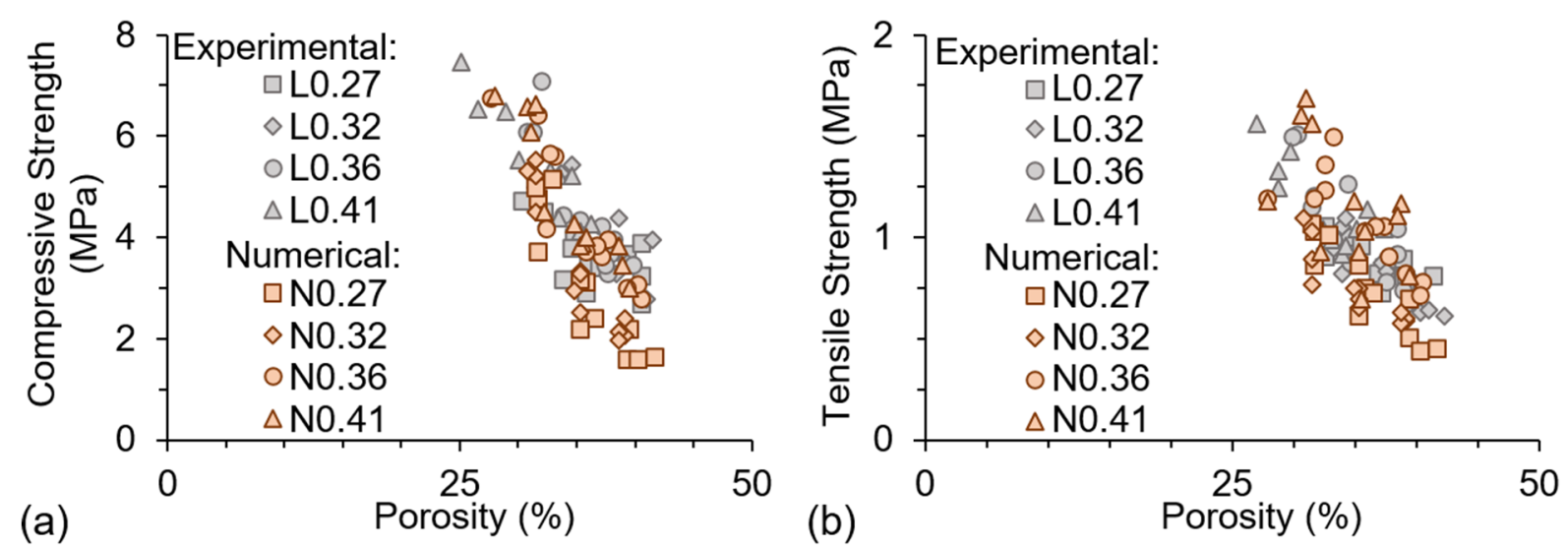

Figure 8. Experimental and numerical results: a) compressive and b) tensile strength [42]. 


\section{References}

[1] S. Barnett, J-F. Lataste, T. Parry, S. Millard, M. Soutsos, Assessment of fibre orientation in ultra high performance fibre reinforced concrete and its effect on flexural strength. Mater Struct (2010) 43(7): 10091023. https://doi.org/10.1617/s11527-009-9562-3

[2] S-T. Kang, J-K. Kim, The relation between fiber orientation and tensile behavior in an Ultra High Performance Fiber Reinforced Cementitious Composites (UHPFRCC). Cem Concr Res (2011) 41(10): 1001-1014. https://doi.org/10.1016/i.cemconres.2011.05.009

[3] S-T. Kang, J-K. Kim, Investigation on the flexural behavior of UHPCC considering the effect of fiber orientation distribution. Constr Build Mater (2012) 28(1): 57-65. https://doi.org/10.1016/j.conbuildmat.2011.07.003

[4] L. Segura-Castillo, SHP. Cavalaro, C. Goodier, A. Aguado, S. Austin, Fibre distribution and tensile response anisotropy in sprayed fibre reinforced concrete. Mater Struct (2018) 51(1): 29. https://doi.org/10.1617/s11527-018-1156-5

[5] JT. Kevern, VR. Schaefer, K. Wang, Evaluation of Pervious Concrete Workability Using Gyratory Compaction. J Mater Civil Eng (2009) 21(12):764-770. https://doi.org/10.1061/(ASCE)0899-1561(2009)21:12(764)

[6] R. Pieralisi, SHP. Cavalaro, A. Aguado, Discrete element modelling of the fresh state behavior of pervious concrete. Cem Concr Res (2016) 90:6-18. https://doi.org/10.1016/i.cemconres.2016.09.010

[7] V. Mechtcherine, S. Shyshko, Virtual concrete laboratory continuous numerical simulation of concrete behaviour from fresh to hardened state. In: Grosse CU (ed) Advances in construction materials. Springer, Berlin-Heidelberg (2007) pp 479-488

[8] A. Orbe, E. Roji, R. Losada, J. Cuadrado, Calibration patterns for predicting residual strengths of steel fibre reinforced concrete (SFRC). Compos Part B-Eng (2014) 58: 408-417. https://doi.org/10.1016/i.compositesb.2013.10.086

[9] N. Roussel, A. Gram, M. Cremonesi, L. Ferrara, K. Krenzer, V. Mechtcherin, S. Shyshko, J. Skocec, J. Spangenberg, S. Oldrich, LN. Thrane, K. Vasilic, Numerical simulations of concrete flow: A benchmark comparison. Cem Concr Res (2016) 79:265-271. https://doi.org/10.1016/j.cemconres.2015.09.022

[10] L. Ferrara, M. Cremonesi, M. Faifer, S. Toscani, L. Sorelli, M-A. Baril, J. Réthoré, F. Baby, F. Toutlemonde, S. Bernardi, Structural elements made with highly flowable UHPFRC: Correlating computational fluid dynamics (CFD) predictions and non-destructive survey of fiber dispersion with failure modes. Eng Struct (2017) 133:151-171. https://doi.org/10.1016/j.engstruct.2016.12.026

[11] R. Deeb, BL.Karihaloo, S. Kulasegaram, Reorientation of short steel fibres during the flow of self-compacting concrete mix and determination of the fibre orientation factor. Cen Concr Res (2014) 56:112-120. https://doi.org/10.1016/j.cemconres.2013.10.002

[12] R. Deeb, S. Kulasegaram, BL. Karihaloo, 3D modelling of the flow of self-compacting concrete with or without steel fibres. Part II: L-box test and the assessment of fibre reorientation during the flow. Computational Particle Mechanics (2014) 1(4):391-408. https://doi.org/10.1007/s40571-014-0003-x

[13] V. Cunha, J. Barros, J. Sena-Cruzb, An integrated approach for modelling the tensile behaviour of steel fibre reinforced selfcompacting concrete. Cem Concr Res (2011) 41(1):64-76. https://doi.org/10.1016/j.cemconres.2010.09.007

[14] V. Mechtcherine, A. Gram, K. Krenzer, J-H. Schwabe, S. Shyshko, N. Roussel, Simulation of fresh concrete flow using Discrete Element Method (DEM): theory and applications. Mater Struct (2014) 47(4): 615-630. https://doi.org/10.1617/s11527-013-0084-7

[15] A. Pros, P. Diez, C. Molins, Modeling steel fiber concrete: numerical immersed boudery approach and a phenomenological mesomodel for concrete-fiber interaction. Int J Numer Methods Eng (2012) 90:65-86. https://doi.org/10.1002/nme.3312

[16] SHP. Cavalaro, A. Aguado, Intrinsic scatter of FRC: an alternative philosophy to estimate characteristic values. Mater Struct (2015) 48:3537-3555. https://doi.org/10.1617/s11527-014-0420-6

[17] A. Naaman, G. Nammur, J. Alwan, H. Najm, Fiber pullout and bond slip. I: analytical study. J Struct Eng (1991) 117(9):2769-2790. https://doi.org/10.1061/(ASCE)0733-9445(1991)117:9(2769)

[18] Y. Wang, VC. Li, S. Backer, Modelling of fibre pull-out from a cement matrix. Int J Cem Compos Lightweight Concr (1998) 10(3):143-149. https://doi.org/10.1016/0262-5075(88)90002-4

[19] A. Bentur, S. Mindess, Fibre reinforced cementitious composites. 2nd edn (2006), 624.
[20] H. Stang, Z. Li, S. Shah, Pullout problem: stress versus fracture mechanical approach. J Eng Mech (1990) 116(10):2136-2150. https://doi.org/10.1061/(ASCE)0733-9399(1990)116:10(2136)

[21] F. Laranejeira, C. Molins, A. Aguado, Predicting the pullout response of inclined straight steel fibers. Mater Struct (2010) 43(6):875-895. https://doi.org/10.1617/s11527-009-9553-4

[22] F. Laranejeira, C. Molins, A. Aguado, Predicting the pullout response of inclined hooked steel fibers. Cem Concr Res (2010) 40(10):14711487. https://doi.org/10.1016/j.cemconres.2010.05.005

[23] C. Leung, N. Shapiro, Optimal steel fiber strength for reinforcement of cementitious materials. J Mater Civ Eng (1999) 11(2):116-123. https://doi.org/10.1061/(ASCE)0899-1561(1999)11:2(116)

[24] A. Van Gysel, Studie van het uittrekgedrag van staalvezels ingebed in een cementgebonden matrix met toepassing op staalvezelbeton onderworpen aan buiging. PhD Thesis Defended at the Gent University. Gent, Belgium 2000.

[25] P. Robins, S. Austin, P. Jones, Pull-out behavior of hooked steel fibres. Mater Struct (2002) 35:434-442. https://doi.org/10.1007/BF02483148

[26] BSI (2005) BS EN 14651:2005+A1:2007 Test method for metallic fibre concrete. Measuring the flexural tensile strength (limit of proportionality (LOP), residual). London, England: British Standards Institution.

[27] A. Blanco, P. Pujadas, A. de la Fuente, S. Cavalaro, A. Aguado, Application of constitutive models in European codes to RC-FRC. Constr Build Mater (2013) 40:246-259. https://doi.org/10.1016/i.conbuildmat.2012.09.096

[28] JM. Torrents, A. Blanco, P. Pujadas, P. Juan-Garcia, MA. SanchezMoragues, Inductive method for assessing the amount and orientation of steel fibres in concrete. Mater Struct (2012) 45(10):1577-1592. https://doi.org/10.1617/s11527-012-9858-6

[29] SHP. Cavalaro, R. Lopez, JM. Torrents, A. Aguado, Improved assessment of fibre content and orientation with inductive method in SFRC. Mater Struct (2015) 48(9):1859-1873. https://doi.org/10.1617/s11527-014-0279-6

[30] SHP. Cavalaro, R. Lopez-Carre-o, JM. Torrents, A. Aguado, P. JuanGarcia, Assessment of fibre content and 3D profile in cylindrical SFRC specimens. Mater Struct (2016) 49(1-2):577-595. https://doi.org/10.1617/s11527-014-0521-2

[31] FIB (2010) Fib Model Code for Concrete Structures, International Federation for Structural Concrete, Lausanne (Switzerland).

[32] AG. Kooiman, Modelling Steel Fibre Reinforced Concrete for Structural Design. PhD dissertation, Delft University of Technology (The Netherlands), 2000.

[33] ES. Bernard, M. Pircher, The influence of thickness on performance of fiber-reinforced concrete in a round determinate panel test. J Cem Concr Aggreg (2001) 23(1).

[34] M. di Prisco, G. Plizzari, L. Vandewalle, Fibre reinforced concrete: new design perspectives. Mater Struct (2009) 42:1261-1281. https://doi.org/10.1617/s11527-009-9529-4

[35] A. de la Fuente, RC. Escariz, AD. Figueiredo, C. Molins, A. Aguado, A new design method for steel fibre reinforced concrete pipes. Constr Build Mater (2012) 30:547-555. https://doi.org/10.1016/i.conbuildmat.2011.12.015

[36] A. de la Fuente, RC. Escariz, AD. Figueiredo, A. Aguado, Design of macro-synthetic fibre reinforced concrete pipes. Constr Build Mater (2013) 43:523-532.

https://doi.org/10.1016/i.conbuildmat.2013.02.036

[37] R. Pieralisi, SHP. Cavalaro, A. Aguado, Evolutionary lattice model for the compaction of pervious concrete in the fresh state. Constr Build Mater (2015) 99:11-25. https://doi.org/10.1016/i.conbuildmat.2015.08.143

[38] R. Pieralisi, SHP. Cavalaro, A. Aguado, Advanced numerical assessment of the permeability of pervious concrete. Cem Concr Res (2017) 102:149-160. https://doi.org/10.1016/j.cemconres.2017.09.009

[39] J. Zhang, G. Ma, R. Ming, X. Cui, L. Li, H. Xu, Numerical study on seepage flow in pervious concrete based on 3D CT imaging, Constr Build Mater (2018) 161:468-478. https://doi.org/10.1016/j.conbuildmat.2017.11.149

[40] C. Lian, Y. Zhuge, S. Beecham, Modelling Pervious Concrete under Compression Loading - A Discrete Element Approach. Adv Materials Res (2011) 168-170:1590-1600.

[41] SP. Singh, KP. Biligiri, Numerical Simulation of Pervious Concrete Using Discrete Element Modeling Technique. J Test Eval (2018) 46(6). https://doi.org/10.1520/JTE20170141

[42] R. Pieralisi, Characterization and modelling of pervious concrete. PhD dissertation, Universitat Politecnica de Catalunya (Spain), 2016. 